\title{
Reflexões acerca do termo paraestatal no direito brasileiro
}

\author{
Reflections on the term paraestatal in the brazilian law
}

Douglas Henrique de Oliveira ${ }^{1}$

\begin{abstract}
Resumo
Trata-se de trabalho realizado a fim de investigar, o significado, origem e 0 alcance do termo Paraestatal no Direito Brasileiro. Para tanto, pretende-se, por meio de investigações no ordenamento jurídico, na doutrina especializada e na jurisprudência do Superior Tribunal de Justiça, demonstrar o quão diversos são os posicionamentos adotados, apontar pela necessidade de reavaliação do termo para conferir caráter científico ao seu significado e, finalmente, sinalizar com a possível solução conferida pelo anteprojeto da lei orgânica que estrutura a Administração Pública Federal.
\end{abstract}

Palavras-Chave: Direito Administrativo; Administração Pública; Paraestatal. Interpretação.

\section{Abstract}

It is a work done to investigate the meaning, origin and scope of the term "Paraestatal" in the Brazilian Law. Therefore, through investigations on the legal system, the specialized doctrine and the Jurisprudence of the Superior Court, we intend to demonstrate how different are the positions taken to point out the need for re-evaluation of the term to entitle a scientific characteristic to its meaning, and finally to indicate the possible solution from the draft of the organic law that structures the Federal Public Administration.

Keywords: Administrative Law; Public Administration; Paraestatal. Interpretation.

\section{Introdução}

A complexidade do mundo jurídico e sua relação com outros campos do conhecimento faz com que, muitas vezes, o jurista busque novos termos para conferir significado a novos institutos e, em último caso, às redações de dispositivos legais que regem a vida em sociedade.

\footnotetext{
${ }^{1}$ Universidade Estadual de Londrina. Contato: douglasoliveira@sercomtel.com.br
} 
Entretanto, não raras vezes, esses termos se desconectam de seus significados originais e incorporam uma carga semântica originada na própria evolução das relações sociais. Há ocasiões, inclusive, em que eles se voltam totalmente contra o significado original, provocando confusões linguísticas que trazem prejuízo à compreensão das ideias.

Da mesma forma, é possível encontrar no ordenamento jurídico termos que são utilizados sem que o seu significado tenha sido devidamente investigado, ou sem que fosse conferida a ele uma delimitação no mundo jurídico, o que pode comprometer a cientificidade do Direito.

Dentre esses termos, certamente se pode indicar o paraestatal, o qual, não obstante 0 uso de longa data a que se tem conhecimento, não recebeu a devida atenção e ainda é utilizado de modo não criterioso no ordenamento jurídico, na doutrina e na jurisprudência.

Diante do tema que se apresenta, pretende-se demonstrar a relevância da discussão, o enquadramento do assunto dentro do Direito Administrativo, os diversos posicionamentos existentes, os possíveis desdobramentos do problema na linguagem jurídica e, por fim, uma possível solução para a controvérsia por meio do anteprojeto que poderá criar a nova lei orgânica da Administração Pública Federal.

\section{A importância da investigação do termo paraestatal no Direito Brasileiro}

O conhecimento vulgar a respeito das leis, entendidas por muitos como enunciados claros e passíveis de fácil interpretação, muitas vezes contrasta com a realidade que o jurista enfrenta em seu dia a dia. A riqueza da língua portuguesa, com seus termos sinônimos e de grande carga semântica, parece dificultar ainda mais o processo de interpretação no Direito.

Dentre esses termos, como já mencionado, encontra-se o paraestatal, que, não obstante o corrente uso no Direito Público ao longo dos últimos anos, ainda precisa ser lapidado, já que seu alcance e seus limites ainda não são consensuais no ordenamento jurídico, doutrina e jurisprudência.

No esforço de levantar as ideias existentes no termo em estudo e buscar a compreensão de sua mensagem, deve-se tomar como ponto de partida a análise literal do vocábulo, investigando sua composição e origem. Neste sentido, são válidas as lições de Reale (2005, p. 279): 
A lei é uma declaração da vontade do legislador e, portanto, deve ser reproduzida com exatidão e fidelidade. Para isto, muitas vezes é necessário indagar o exato sentido de um vocábulo ou do valor das proposições do ponto de vista sintático. A lei é uma realidade morfológica e sintática que deve ser, por conseguinte, estudada do ponto de vista gramatical.

A esse respeito, também ensina M ontoro (2000, p. 31):

0 estudo das palavras e da linguagem em geral é da maior importância. Quando um vocábulo é empregado durante várias gerações para designar uma realidade, ele se apresenta cheio de conteúdo e significação. 0 nome é a experiência acumulada e constitui, de certa forma, o limiar da ciência.

Com relação ao proposto, Carvalho Filho (2008, p. 434) ao analisar a composição do termo, ensina que a palavra paraestatal tem formação híbrida, pois, enquanto o prefixo para é de origem grega, o vocábulo status é de origem latina. Assim, "paraestatal significa ao lado do Estado, paralelo ao Estado".

Ademais, Mello (apud DI PIETRO, 2003, p. 412) revela que o termo fora empregado pela primeira vez no direito italiano, por ocasião de um decreto-lei em 1924, para indicar a existência de certos entes que formariam uma categoria intermediária entre as pessoas públicas e privadas.

Apesar da aparente tranquilidade que inspira a visualização do termo em sua composição, as paraestatais são objeto de grande divergência no Direito Brasileiro. Até hoje, não se conseguiu chegar a uma conclusão sobre quais entidades e entes despersonalizados poderiam compor o gênero das paraestatais.

Como consequência do exposto, a confusão semântica impede a correta sistematização e classificação de determinados institutos na doutrina administrativa e compromete até mesmo a utilização de outro termo de corrente uso no Direito, a saber, o vocábulo estatal, pois se não se consegue delinear o paraestatal, há claro comprometimento de sua expressão antônima.

Não obstante, vários são os sentidos que leis, doutrinadores e tribunais têm emprestado à expressão, o que não só deixa dúvidas ao intérprete quando com ela se depara, como também imprime indesejável imprecisão jurídica, que em nada contribui para a ciência do Direito. (CARVALHO FILHO, 2008, p. 434). 
Mas, afinal, quais são as divergências existentes em relação ao termo paraestatal a que até o momento se fez referência? Como se posiciona o ordenamento jurídico, a doutrina e a jurisprudência em relação ao tema?

\section{Construção de um caminho para a identificação das divergências quanto ao tema das paraestatais}

A busca por uma resposta para os questionamentos suscitados perpassa necessariamente pelo resgate de algumas noções do Direito Administrativo no que tange a sua função e organização.

Portanto, de modo singelo e para alcançar os fins aqui propostos pelo presente estudo, resta lembrar que a Administração Pública, em sentido funcional, representa um conjunto de atividades que visam prestar de serviços, bens e utilidades com o intuito de alcançar os fins colimados na ordem jurídica.

Trata-se da própria gestão dos interesses públicos executada pelo Estado, seja através da prestação de serviços públicos, seja por sua organização interna, ou ainda pela intervenção no campo privado, algumas vezes até de forma restritiva (poder de polícia) (CARVALHO FILHO, 2008, p. 10).

Para isso, a Administração faz uso de alguns mecanismos para se organizar, já que diante das demandas que se impõe em face do modelo de Estado Social e da vastidão do território brasileiro, a execução de algumas tarefas poderia ser prejudicada por conta da burocracia e morosidade.

Na organização administrativa brasileira há uma divisão vertical (que não significa hierarquia entre os níveis), decorrente da forma federativa. Segundo esse critério, existe a Administração Federal, a Administração Estadual, a Administração do Distrito Federal e a Administração M unicipal (MEDAUAR, 2008. p. 50).

Além do mencionado aspecto, nesse processo de organização, surge, conforme ensina Di Pietro (2003, p. 412), a noção de desconcentração, ou seja, a distribuição interna de competências dentro do próprio ente administrativo, e a descentralização, compreendida como a distribuição de competências de uma para outra pessoa jurídica.

Como consequência do processo de desconcentração, estrutura-se a Administração Direta, e da descentralização, a Administração Pública Indireta, que, conforme 0 artigo 4ํㅗII, 
do decreto-lei 200/67, compreende as autarquias, empresas públicas, sociedades de economia mista e fundações públicas.

Entretanto, a dinâmica dos acontecimentos em nossa sociedade fez com que novas demandas surgissem sem que o Estado pudesse utilizar as estruturas jurídicas existentes para ampará-las, cedendo espaço para que novos agentes passassem a atuar paralelamente ao Estado.

Ao Estado compete também, por cometimento constitucional ou legal, exercer inúmeras atividades administrativas impróprias, ou seja, que não necessitem ser por ele desempenhadas, o que ocorre, principalmente na prestação de serviços públicos, de atividades de ordenamento econômico, de ordenamento social e, notadamente, de fomento público (M OREIRA NETO, 2006, p. 260).

Neste sentido, assevera M edauar (2008, p. 94) que há "inúmeros entes dotados de características que não se enquadram exatamente nos moldes previstos legalmente para identificar as entidades componentes da Administração Indireta, nem permitem situá-los como órgãos da Administração Direta".

Dentre os entes a que a autora acima faz referência, a doutrina aponta a existência de ordens e conselhos profissionais, destinados a administrar o exercício de profissões, fundações de apoio, que mantêm convênios, ajustes e contratos com universidades ou faculdades, os serviços sociais autônomos, destinados a propiciar assistência social, médica ou ensino à população ou a certos grupos profissionais, e as concessionárias de serviços públicos.

Ademais, pode-se fazer menção às organizações sociais, reguladas pela lei 9637/98, que desenvolvem atividades dirigidas ao ensino, à pesquisa científica, ao desenvolvimento tecnológico, à proteção e preservação do meio ambiente, à cultura e à saúde, e as organizações da sociedade civil de interesse público, reguladas pela lei 9790/99, as quais também desenvolvem atividades de interesse público.

É justamente quando se vislumbra a estrutura administrativa criada pelo decreto-lei 200/67 somada com os novos entes ora mencionados que surgem as divergências e, consequentemente, 0 objeto deste trabalho. Em meio aos entes personalizados que até 0 momento se apresentam, o que pode ser denominado de paraestatal ou não? 


\section{Os posicionamentos extraídos do Ordenamento Jurídico}

Sem pretensões de por um ponto final à questão, mas de tão somente apresentar o problema de modo mais abrangente, realizou-se em 16 de Agosto de 2011 uma pesquisa no site da Câmara dos Deputados ${ }^{2}$ por legislações que relacionassem o termo paraestatal.

Dentre leis ordinárias e complementares, foram encontrados 20 (vinte) diplomas normativos em plena vigência. Em uma análise individualizada, o que se verificou é que 0 termo paraestatal não é utilizado de modo cientifico, pois os significados a ele atribuídos são variados.

Existem leis que utilizam o termo para fazer referência a todas as pessoas jurídicas que não compõem a Administração Pública Direta. Há outras, por sua vez, que utilizam o termo para se referir às pessoas jurídicas que não compõe a Administração Pública Direta e Indireta.

Ademais, há leis que indicam de modo residual ser paraestatal tudo que não pertença à Administração Pública Direta e que não seja autarquia, assim como também se encontra legislações que excluem da incidência do termo, além dos entes da Administração Pública Direta e Indireta, as entidades controladas pelo Poder Público e as concessionárias de serviços públicos.

0 descenso é tamanho que é possível encontrar leis que fazem uso da expressão órgão paraestatal, dando a entender pela possibilidade da existência de entes despersonalizados que poderiam fazer parte do gênero paraestatal. M as o problema não fica adstrito ao campo legislação. Na doutrina especializada, a questão também é alvo de embate.

\section{As paraestatais segundo a doutrina do Direito Administrativo}

$\mathrm{Na}$ tentativa de trazer a discussão para o campo acadêmico, realizou-se levantamento em alguns célebres cursos e manuais de Direito Administrativo, bem como em nos mais conhecidos dicionários jurídicos produzidos no Brasil, sobre os quais insta primeiro expor.

\footnotetext{
${ }^{2}$ http://www2.camara.gov.br/.
} 
Nesse sentido, Sidou (1997, p. 568), em seu Dicionário Jurídico, sem tentar lapidar o tema, expõe que paraestatal é a qualidade de certos entes que, sem integrarem a administração do Estado, com ela colaboram na realização de serviços tendentes à satisfação das necessidades coletivas.

Na mesma linha, Silva (2005, p. 1002) e Diniz (2005, p. 576), acompanham o disposto pelo autor ao afirmarem que paraestatal é a qualidade de determinada entidade, que, apesar de não ser parte integrante da Administração Pública, com ela colabora na prestação de serviços que promovem o bem-estar social e atendem ao interesse da coletividade. Ademais, ao final da análise do vocábulo, os autores citam como exemplo de paraestatal as entidades autárquicas, ideia também partilhada por Cretella Junior (apud Carvalho Filho, 2008, p. 434).

A respeito dos conceitos apresentados pelos três autores, nas suas respectivas obras, nota-se certa superficialidade, por não conferir um norte à questão, e a existência de contradição, por mencionar como exemplo de paraestatal uma entidade que, em ultima ratio, integra a Administração Pública e apresenta forte vínculo com a Administração Pública Direta. M as a questão também recebe tratamento em obras da doutrina administrativista.

Para Carvalho Filho (2008, p. 435), o termo deveria abranger de modo amplo a Administração Indireta e os serviços sociais autônomos, pois ou a pessoa caracteriza-se como estatal, se for integrante do próprio Estado, como é o caso das pessoas federativas, ou terá ela que qualificar-se como paraestatal, por atuar em direta colaboração com o Estado por força do vínculo jurídico formal.

Um pouco mais restrita é a posição de Moreira Neto (2006, p. 261, 266-267), para quem as "paraestatais são pessoas jurídicas de direito privado, criadas por lei para desempenhar, por delegação legal, atribuições de natureza executiva no campo das atividades sociais e econômicas cometidas ao Estado." 0 autor também frisa que não fazem parte deste grupo os serviços sociais autônomos, os quais foram excluídos da Administração Indireta, e os conselhos de fiscalização do exercício profissional, que resultaram da transformação de autarquias corporativas em pessoas jurídicas de direito privado.

Segundo Ferreira (apud Carvalho Filho, 2008, p. 434), as paraestatais seriam pessoas jurídicas de direito privado integrantes da Administração Indireta, excluindo-se, por conseguinte, as autarquias, as fundações de direito público e os serviços sociais autônomos. 
Por outro lado, para Justen Filho (2009, p. 223), o termo se limita justamente aos serviços sociais autônomos, destinados a promover 0 atendimento de necessidades assistenciais e educacionais de certas atividades ou categorias profissionais, que arcam com sua manutenção mediante contribuições compulsórias.

Um pouco mais amplo é o posicionamento de Nohara (2011, p. 600), para quem as paraestatais são os entes que não integram a Administração Pública Direita nem Indireta, pois não há vínculo delas com a estrutura administrativa do Estado, podendo-se mencionar como principal exemplo, as corporações profissionais e os serviços sociais autônomos.

Di Pietro (2003, p. 414), no mesmo sentido adotado por Mello (apud Di Pietro, 2003, p. 414), entende que as paraestatais, por atuarem ao lado do Estado, recebem a denominação de entidades integrantes do chamado terceiro setor e abrangem as declaradas de utilidade pública, as que recebem certificado de fins filantrópicos, os serviços sociais autônomos (SESI, SESC, SENAI), as organizações sociais e as organizações da sociedade civil de interesse público.

Por fim, segundo M eirelles (2008, p. 68), são espécies de entidades paraestatais, também denominadas de entes em cooperação com o Estado, os serviços sociais autônomos (SESI, SESC, SENAI e outros) e, agora, as organizações sociais, cuja regulamentação foi aprovada pela lei $9.648 / 98$.

Portanto, verifica-se que os significados e amplitude conferida ao termo são os mais diversos possíveis entre os autores de diferentes gerações do Direito da Administração, o que mostra que a doutrina também sente dificuldade para encontrar um caminho para a classificação das paraestatais. No entanto, as divergências também adentram o campo jurisprudencial.

\section{As paraestatais segundo o Superior Tribunal de Justiça}

Para estender a discussão também ao campo jurisprudencial, realizou-se em 16 de Agosto de 2011 uma pesquisa no site do Superior Tribunal de Justiça ${ }^{3}$ por acórdãos que relacionassem o termo paraestatal, no período de Janeiro de 2000 à Agosto de 2011.

\footnotetext{
${ }^{3}$ http://stj.jus.br.
} 
Entre os 54 (cinquenta e quatro) acórdãos encontrados e analisados isoladamente, constatou-se que o uso do termo também carece de maior precisão e caráter científico, pois foi utilizado de forma até contraditória em determinados momentos.

Em meio aos vários acórdãos, insta mencionar, de modo cronológico, alguns em que a corte, modo indireto, se posicionou sobre o tema:

PREVIDENCIÁRIO. PROCESSUAL CIVIL. AÇÃO DE COM PLEM ENTAÇÃO DE BENEFÍCIOS PREVIDENCIÁRIOS. LEI № 6.899/81. PREQUESTIONAMENTO. AUSÊNCIA. OBRIGAÇÃO DE TRATO SUCESSIVO. PRESCRIÇÃO. - O instrumento processual do recurso especial tem como pressuposto de admissibilidade 0 debate da questão federal pelo Tribunal de origem, a fim de restar configurado o prequestionamento que viabiliza a abertura da instância extraordinária. - A prescrição qüinqüenal das ações contra a Fazenda Pública, bem como suas autarquias e entidades paraestatais atinge o fundo de direito quando 0 ato lesivo da Administração negar a situação jurídica fundamental em que se embasa a pretensão veiculada. - $\mathrm{Na}$ hipótese, encontrando-se a situação jurídica consolidada pelo pagamento mensal dos benefícios previdenciários e objetivando-se a complementação a fim de que tenham valores inferiores ao salário-mínimo, aplica-se o comando incerto na Súmula $n$ ㅇ 85/STJ, que disciplina a prescrição qüinqüenal nas relações de trato sucessivo, em que são atingidas apenas as parcelas relativas ao qüinqüênio antecedente à propositura da ação. - Recurso especial parcialmente conhecido e nesta extensão provido. (REsp 203.957/CE, Rel. Ministro VICENTE LEAL, SEXTA TURM A, julgado em 29/03/2000, DJ 24/04/2000, p. 78, grifo nosso).

Em relação ao julgado supra de Abril de 2000, há que se notar que o Superior Tribunal de Justiça na oportunidade excluiu do grupo das paraestatais a entidade autárquica e a Fazenda Pública, ao fazer menção a estas de modo individualizado.

PROCESSO CIVIL E ADMINISTRATIVO - CADERNETA DE POUPANÇA: BLOQUEIO PRESCRIÇÃO QÜINQÜENAL. 1. As autarquias, por expressa determinação legal, estão ao abrigo da prescrição qüinqüenal. 2. Diferentemente das demais entidades paraestatais (empresas públicas e sociedades de economia mista), as autarquias estão sempre favorecidas com a redução do lapso prescricional. Inteligência do art. 2ำ do DL n. 4.597/42. 3. Além da norma de caráter geral, o BACEN tem o favor legal pelo contido no art. 50 da Lei n. 4.595/64, dispositivo que estende nominalmente ao recorrente os benefícios e privilégios da Fazenda Nacional. 4. Recurso especial provido. (REsp 247.825/RS, Rel. Ministra ELIANA CALM ON, SEGUNDA TURMA, julgado em 05/12/2000, DJ 12/02/2001, p. 105, grifo nosso).

Entretanto, no mesmo ano, em outra decisão a corte fez referência expressa sobre quais entes personalizados fariam parte do rol das estatais: autarquias, empresas públicas e sociedades de economia mista, sem, contudo, adentrar na discussão a respeito da terminologia. 
PROCESSUAL CIVIL E ADMINISTRATIVO - REPETIÇÃO DO INDÉBITO - TARIFA DE ENERGIA ELÉTRICA - MAJORAÇÃO - PORTARIAS DNAEE 38 E 45/86 ILEGITIMIDADE - DECRETOS-LEIS 2.283 E 2.284, DE 1986 - PRESCRIÇÃO VINTENÁRIA - PAGAMENTO NÃO ESPONTÂNEO - ERRO NO RECOLHIMENTO PROVA DESNECESSÁRIA - PRECEDENTES. - É ilegítima a majoração da tarifa de energia elétrica determinada pelas Portarias 38 e 45/86 do DNAEE, tendo em vista 0 congelamento estabelecido pelos arts. 35 e 36, respectivamente, dos Decretosleis 2.283 e 2.284, de 1986. O mesmo não ocorre, porém, a partir da edição da Portaria 153/86 do DNAEE. - Não sendo a Eletropaulo, empresa fornecedora de energia elétrica, entidade paraestatal, não se aplica a prescrição quinquenal, sujeitando-se as suas dívidas passivas ao prazo vintenário. - A restituição das quantias pagas indevidamente a título de tarifa de energia elétrica não depende da comprovação do erro no recolhimento, por isso que se trata de pagamento não espontâneo, ficando o usuário sujeito a juros de mora e a corte de energia se não efetuar o pagamento até o vencimento. - Recurso especial conhecido e provido, invertidos os ônus da sucumbência. (REsp 232.275/SP, Rel. Ministro FRANCISCO PEÇANHA MARTINS, SEGUNDA TURM A, julgado em 23/10/2001, DJ 29/04/2002, p. 211, grifo nosso).

Neste julgado é possível analisar um dos pontos nebulosos na utilização do termo paraestatal, a saber, a decisão sobre incluir ou não no gênero as concessionárias de serviços públicos. Na oportunidade, o Superior Tribunal de Justiça se posicionou no sentido de que não podem ser consideradas paraestatais as concessionárias de serviços públicos.

No entanto, é importante desde já chamar a atenção para uma mudança de comportamento do tribunal, que, em julgado mais recente, o qual ainda será apresentado, referiu-se a elas como paraestatais.

PROCESSO CIVIL - RECURSO ESPECIAL - MANDADO DE SEGURANÇA - CONCURSO PÚBLICO - APROVADO PRETERIDO EM SUA NOMEAÇÃO E POSSE E, POSTERIORM ENTE, ANISTIADO - OMISSÃO NO CUM PRIM ENTO PELO DIRIGENTE DE SOCIEDADE DE ECONOMIA MISTA - BANCO DE BRASÍLIA - BRB - ATO DE AUTORIDADE E NÃO DE GESTÃO - LEGITIMIDADE PASSIVA AD CAUSAM RECONHECIDA - PREJUDICIAL AFASTADA. 1 - 0 dirigente da Sociedade de Economia $M$ ista submete-se, quando pratica atos típicos do Direito Público, aos princípios que vinculam toda a Administração, como a moralidade, legalidade, impessoalidade, etc. Logo, tais atos não podem ser classificados como meros atos de gestão, o que descaracterizaria a simbiose de sua personalidade jurídica. Sendo o Banco de Brasília - BRB um ente paraestatal e seu administrador nomeado, inclusive, pelo Poder Público, a impugnação do ato omissivo que não acatou a anistia homologada, a qual determinou a nomeação e posse do recorrente, aprovado em concurso público para o cargo de Economista, é passível de impugnação através do remédio constitucional do mandado de segurança. Inteligência do art. 1으, da Lei $n$ o 1.533/51. 2 - Recurso conhecido e provido para, reformando in totum o v. acórdão de origem, rejeitar a preliminar que declarou incabível o mandado de segurança e determinar o retorno dos autos ao Tribunal de a quo, para que julgue o mérito da impetração. (REsp 413.818/DF, Rel. M inistro JORGE SCARTEZINI, QUINTA TURM A, julgado em 27/05/2003, DJ 23/06/2003, p. 409, grifo nosso). 
No que tange ao julgado em testilha de Maio de 2003, a Corte faz, novamente, 0 uso da terminologia para tratar das sociedades de economia mista, caso do Banco de Brasília (BRB).

PROCESSUAL CIVIL. AÇÃO POPULAR. SEBRAE/SC NO PÓLO PASSIVO. COM PETÊNCIA PARA JULGAM ENTO: JUSTIÇA ESTADUAL. 1. O SEBRAE possui natureza de entidade paraestatal, constituído na forma de serviço social autônomo mantido por contribuições parafiscais, sujeitando-se ao controle do bom uso de seus recursos pela via da ação popular. Tal equiparação legal, porém, não tem o condão de conferir à Justiça Federal a competência para processar e julgar o feito. 2 . Precedentes desta Corte. 3. Recurso especial provido para assegurar que a ação popular seja julgada perante a Justiça Estadual. (REsp 530.206/SC, Rel. Ministro JOSÉ DELGADO, PRIM EIRA TURM A, julgado em 06/11/2003, DJ 19/12/2003, p. 358)

CONFLITO DE COM PETÊNCIA. JUSTIÇA ESTADUAL E JUSTIÇA FEDERAL. CRIME DE PECULATO E APROPRIAÇÃO INDÉBITA PRATICADO EM DETRIMENTO DO SERVIÇO NACIONAL DE APRENDIZAGEM COMERCIAL - SENAC. ENTIDADE PARAESTATAL SUJEITA AO CONTROLE DO TRIBUNAL DE CONTAS DA UNIÃO. APLICAÇÃO DA SÚM ULA 208 DESTE SODALÍCIO. COM PETÊNCIA DA JUSTIÇA FEDERAL. 1. O ServiçO Nacional de Aprendizagem Comercial - SENAC, por ser entidade paraestatal com atuação em todo território nacional, está sujeita ao controle e fiscalização pelo Tribunal de Contas da União. 2. Aplicação do Verbete Sumular n. 0208 desta Corte, que enuncia ser competência da Justiça Federal a instrução e julgamento de ilícitos praticados por Prefeitos M unicipais em detrimento de verbas sujeitas prestação de contas perante órgão federal. 3. Conflito conhecido para declarar competente 0 Juízo da 3a vara Federal Criminal da Subseção Judiciária de Porto Alegre/ RS. (CC 66.354/RS, Rel. Ministra MARIA THEREZA DE ASSIS MOURA, TERCEIRA SEÇÃO, julgado em 28/02/2007, DJ 26/03/2007, p. 201, grifo nosso).

No que refere aos dois casos elencados, o Superior Tribunal de Justiça fez uso do termo paraestatal para se referir aos serviços sociais autônomos, algo muito comum de se visualizar nos casos mais recentes da corte.

PROCESSUAL CIVIL. EXECUÇÃO. PARANAPREVIDÊNCIA. ENTIDADE PARAESTATAL. LEI ESTADUAL N. 12.398/98. INAPLICABILIDADE DO RITO PREVISTO NO ART. 730 DO CPC. DECISÃO M ONOCRÁTICA FUNDAM ENTADA EM JURISPRUDÊNCIA DOMINANTE DESTA CORTE SUPERIOR E DO STF. 1. Na decisão monocrática, aplicou-se a jurisprudência firme desta Corte Superior no sentido de que as prerrogativas processuais destinadas à Fazenda Pública, mormente a prevista no artigo 730 do CPC, não são extensivas à Paranaprevidência, nem a outros serviços autônomos. 2. Ademais, o Supremo Tribunal Federal já fixou entendimento no sentido de que as entidades paraestatais que possuem personalidade de pessoa jurídica de direito privado - caso da Paranaprevidência - não fazem jus aos privilégios processuais concedidos à Fazenda Pública (Al 783136 AgR, Relator(a): M in. Eros Grau, Segunda Turma, public. 14-05-2010 Ement Vol-02401-13 pp-02747 RT v. 99, n. 899, 2010, p. 119-122). 3. Agravo regimental não provido. (AgRg no Ag 1348719/PR, Rel. Ministro MAURO CAM PBELL MARQUES, SEGUNDA TURMA, julgado em 14/12/2010, DJe 08/02/2011, grifo nosso). 
Em relação ao caso em tela, mais uma vez o Superior Tribunal de Justiça usa 0 termo para se referir aos órgãos sociais autônomos, no caso, de previdência e de serviços médico-hospitalares, situação da Paraná Previdência, instituída pela lei estadual 12.398/98 e que até esta data era entidade autárquica.

AÇÃO DE INDENIZAÇÃO. ATROPELAMENTO DE PEDESTRE EM VIA PÚBLICA. PENSIONAMENTO. CONSTITUIÇÃO DE CAPITAL. EM PRESA CONCESSIONÁRIA DE SERVIÇO PÚBLICO. NECESSIDADE. PRECEDENTES. DANO M ORAL. MÃE E IRM ÃOS DA VÍTIMA. MAJORAÇÃO DO QUANTUM INDENIZATÓRIO. I - "Em ação de indenização, procedente o pedido, é necessária a constituição de capital ou caução fidejussória para a garantia de pagamento da pensão, independentemente da situação financeira do demandado" (Súmula 313/ST) e independentemente de tratar-se de entidade paraestatal. II - A indenização fixada na origem é ínfima e destoa dos valores aceitos por esta Corte para casos semelhantes, isto é, de dano moral decorrente de morte de familiar em acidente de trânsito, devendo, portanto, ser majorada. Recurso especial provido. (REsp 921.499/RJ, Rel. Ministro SIDNEI BENETI, TERCEIRA TURMA, julgado em 20/10/2009, DJe 03/11/2009, grifo nosso).

No acórdão em tela, o Superior Tribunal de Justiça se posicionou indiretamente no sentido de que as Concessionárias de Serviço Público, caso da CEDAE (Companhia Estadual de Águas e Esgotos), são consideradas paraestatais, contrariando posicionamento que firmara anos atrás.

PROCESSUAL CIVIL. EXECUÇÃO. AGRAVO REGIMENTAL NO AGRAVO DE INSTRUM ENTO. AUSÊNCIA DE PROCURAÇÃO. SÚMULA 115/ST].

PARANAPREVIDÊNCIA. PESSOA JURÍDICA DE DIREITO PRIVADO. PRIVILÉGIOS PROCESSUAIS DA FAZENDA PÚBLICA. NÃO CABIM ENTO. AGRAVO NÃO PROVIDO. 1. $\mathrm{Na}$ instância especial é inexistente recurso interposto por advogado sem procuração nos autos, com fundamento na Súmula 115/ST]. 2. "O Supremo Tribunal Federal fixou entendimento no sentido de que as entidades paraestatais que possuem personalidade de pessoa jurídica de direito privado não fazem jus aos privilégios processuais concedidos à Fazenda Pública" (STF - Al 783.136 AgR/PR, Rel. M in. EROS GRAU, Segunda Turma, DJe 14/5/10) 3. Agravo regimental não provido. (AgRg no Ag 1360016/PR, Rel. Ministro ARNALDO ESTEVES LIMA, PRIMEIRA TURMA, jul gado em 07/06/2011, DJe 20/06/2011, grifo nosso).

Por fim, mais um julgado envolvendo a Paraná Previdência. No mais, chama atenção o caso por fazer alusão ao Supremo Tribunal Federal, que assim como o Superior Tribunal de Justiça, analisou casos envolvendo as mencionadas paraestatais (mas em número bem menor), sem que adentrasse a fundo o estudo da terminologia.

Assim, é clarividente perceber que a própria jurisprudência pátria diverge a respeito do uso da terminologia paraestatal, cujo significado sofreu mutações no decurso dos anos os 
quais foram objeto desse breve levantamento, sem que fosse possível estabelecer um norte para o esclarecimento de sua abrangência.

\section{0 anteprojeto da nova lei orgânica da Administração Pública e os possíveis desdobramentos na delimitação do termo paraestatal}

Conforme exaustivamente esposado, as divergências quanto ao tema nos meios de pesquisa utilizados por este trabalho dificultam o apontamento de uma direção quanto à delimitação do termo paraestatal no Direito Brasileiro.

No entanto, a título de indicar os possíveis caminhos que poderão ser tomados para o aclaramento da questão no futuro, é válido trazer para essa discussão algumas notas em relação ao anteprojeto que confere novo tratamento à estrutura orgânica da Administração Pública Federal.

Trata-se este de um anteprojeto o qual estabelece normas gerais sobre a Administração Pública Direta e Indireta, as Entidades Paraestatais e as de Colaboração, elaborado por uma comissão de respeitáveis juristas nomeados por meio da portaria número 426 do Ministério do Planejamento.

Dentre as virtudes da iniciativa, encontra-se a de tratar, de modo sistematizado, sobre os entes que atuam paralelamente ao Estado, as chamadas entidades paraestatais, grupo no qual seria incluído tão somente as corporações profissionais e os serviços sociais autônomos.

Em relação à demarcação proposta para o tema, válidas são as considerações dos membros da comissão no relatório final que precede os dispositivos do anteprojeto:

Continuam sendo considerados como entidades paraestatais, como sempre o foram, os serviços sociais autônomos que, criados com autorização legislativa, recebem contribuições compulsórias dos empregadores, com fundamento no artigo 240 da Constituição e prestam serviço social e de formação profissional, sendo vinculadas ao sistema sindical.

No entanto, o anteprojeto dá uma configuração um pouco ampliada para abranger, além dos serviços sociais autônomos, outras entidades que exercem atividades públicas e que também são criadas com autorização legislativa.

Nessa categoria se incluem as chamadas corporações profissionais, tais como OAB, CREA, CREM e outras semelhantes que, por exercerem atividade de polícia (melhor se diria atividade disciplinar), de regulação e de repressão sobre os seus associados, têm que ser tratadas como pessoas jurídicas de direito público, no que diz respeito a esse seu papel fiscalizador, regulador e sancionador, que constitui sua atividadefim (SILVA. et al., 2011). 
Constata-se, por derradeiro, que o posicionamento trazido pelo anteprojeto vai de encontro ao ensinado por Nohara (2011, p. 600) e sustentado parcialmente por Justen Filho (2009, p. 223). Outrossim, é certo que não fulmina as discussões acerca da delimitação do tema, mas oferece um posicionamento, o qual, se adotado, poderia mitigar ou fulminar a problemática hoje existente sobre a terminologia em questão.

\section{Conclusão}

Pode-se inferir, a partir de tudo até então exposto, que a utilização do termo paraestatal ainda encontra muitas dificuldades dentro do Direito Brasileiro e merece ser reavaliada. Leis ordinárias e complementares, doutrina e jurisprudência do Superior Tribunal de Justiça ainda não encontraram uma delimitação quanto às pessoas jurídicas e possíveis entes despersonalizados que podem ser considerados como integrantes desse gênero jurídico.

Em razão do ora mencionado, a imprecisão jurídica dificulta sua utilização pelos juristas, a ponto se indicar que sua utilização em nada contribui para a Ciência do Direito e que, aos poucos, poderá cair em desuso na linguagem técnica do Direito, cada vez mais atenta ao conteúdo semântico de suas terminologias.

Noutro giro, é importante retomar outro ponto suscitado durante o trabalho. A dificuldade em criar limites para o uso do termo paraestatal compromete a utilização de outro termo comum no Direito, a saber, o estatal, que poderá com o tempo sofrer as consequências supramencionadas.

Por fim, importante retomar mais uma vez o trabalho desenvolvido por uma comissão designada pelo Ministério do Planejamento, a qual concebeu um anteprojeto para criar a lei orgânica que reestruturaria a Administração Pública Federal e poderia por fim às confusões que permeiam a utilização do termo paraestatal. 


\section{Referências}

CÂM ARA DOS DEPUTADOS. Disponível em:

বhttp://www2.camara.gov.br/busca/?o=relevance $\& \mathrm{v}=$ legislacao $\&$ colecao $=\$ \&$ expressao $=p a r$ aestatal $\&$ palavraschave $=$ paraestatal\&apelid $0=$ paraestatal $\&$ primeiraementa $=$ paraestatal $\& c 0$ rpododocumento $=$ paraestatal $\&$ numero $=\& a n o=\&$ tiponormaF $=$ Lei+Complementar\&tiponorm aF =Lei+Ordin\%C3\%Alria\&di $=\& d f=\&$ origensF $=\&$ situacao $\Rightarrow$. Acesso em: 16 ago. 2011.

CARVALHO FILHO, José dos Santos. Manual de direito administrativo. 20. ed. Rio de Janeiro: Lumen luris, 2008.

DI PIETRO, Maria Sylvia Zanella. Direito administrativo. 15. ed. São Paulo: Atlas, 2003.

DINIZ, M aria Helena. Dicionário jurídico. 2. ed. São Paulo: Saraiva, 2005. v. 3.

JUSTEN FILHO, Marçal. Curso de direito administrativo. 4. ed. São Paulo: Saraiva, 2009.

M EDAUAR, Odete. Direito administrativo moderno. 12. ed. São Paulo: Revista dos Tribunais, 2008.

M EIRELLES, Hely Lopes. Direito administrativo brasileiro. 34. ed. São Paulo: M alheiros, 2008.

M ONTORO, André Franco. Introdução à ciência do direito. 25. ed. São Paulo: Revista dos Tribunais, 2000.

M OREIRA NETO, Diogo de Figueiredo. Curso de direito administrativo. 14. ed. Rio de Janeiro: Forense, 2006.

NOHARA, Irene Patrícia. Direito administrativo. São Paulo: Atlas, 2011.

REALE, M iguel. Lições preliminares de direito. 27. ed. São Paulo: Saraiva, 2005.

SIDOU, José M aria Othon. Dicionário jurídico: academia brasileira de letras jurídicas. 4. ed. Rio de Janeiro: Forense Universitária, 1997.

SILVA, Almiro do Couto et al. Comissão de Juristas constituída pela portaria no 426, de 6 de dezembro de 2007, do Ministério do Planejamento, orçamento e gestão: resultado final. Disponível em:

বhttp://www.planejamento.gov.br/secretarias/upload/Arquivos/seges/comissao_jur/arquiv os/090729_seges_Arq_leiOrganica.pdf>. Acesso em: 9 Nov. 2011. -

SILVA, Oscar Joseph de Plácido. Vocabulário jurídico. 26. ed. Rio de Janeiro: Forense, 2005.

SUPERIOR TRIBUNAL DE JUSTIÇA. Disponível em:

বtttp:// www.stj.jus.br/SCON/jurisprudencia/toc.jsp?tipo_visualizacao =null\&data=\%40DTDE $+\% 3 \mathrm{E} \% 3 \mathrm{D}+20000101+\mathrm{e}+\% 40 \mathrm{DTDE}+\% 3 \mathrm{C} \% 3 \mathrm{D}+20110816 \&$ livre=paraestatal $\& b=\mathrm{ACOR}>$. Acesso em: 12 maio 2011. 
Artigo recebido em:

22 ago. 2011

Artigo aprovado em:

13 nov. 2011 